\title{
Synkopen und die Gene
}

Manche Menschen fallen ungewöhnlich häufig in Ohnmacht, etwa wenn sie Blut sehen oder in plötzlich auftretenden Stresssituationen. Diese Anfälligkeit ist vermutlich in den Genen lokalisiert, ergab jetzt eine Zwillingsstudie.

- Australische Wissenschaftler befragten 51 Zwillingspaare zwischen neun und 69 Jahren, von denen mindestens ein Zwilling Ohnmachtsanfälle durchgemacht hatte. Die Krankenakten der Befragten wurden nach einem standardisierten Fragebogen ausgewertet. Informationen $\mathrm{zu}$ Synkopen bei Verwandten ersten und zweiten Grades wurden ebenfalls eingeholt.

Bei den eineiigen Zwillingen waren doppelt so häufig beide Geschwister von häufigen Ohnmachtsanfällen betroffen wie bei den zweieiigen $(p=0,06)$. Eineiige Zwillinge reagierten auch deutlich häufiger auf die gleichen Auslöser wie Stress oder Blut $(\mathrm{p}<0,001)$. Dass vermutlich mehrere Gene beteiligt sind, schlossen die Wissenschaftler aus der Befragung von Familienangehörigen der Zwillinge.

\section{Kommentar}

Jeder Vierte erlebt mindestens einmal in seinem Leben eine vasovagale Ohnmacht. Bislang war umstritten, ob die Neigung zu den Ohnmachtsanfällen eher genetisch bedingt ist oder durch Umweltfaktoren beeinflusst wird. Jetzt zeigt sich, dass die erbliche Veranlagung vermutlich dann ausschlaggebend ist, wenn die Bewusstlosigkeit häufig auftritt und durch die typischen Auslöser verursacht wird. Bei seltenen Blackouts ohne klassische Auslöser spielen dagegen Umweltfaktoren die dominierende Rolle.

K. MALBERG

- K. M. Klein et al.

Evidence for genetic factors in vasovagal syncope. A twin-family study. Neurology 2012, 79, 561-565; doi: 10.1212/ WNL.0b013e3182635789 